\title{
A randomized phase-I/II multicenter study of recombinant human granulocyte-macrophage colony-stimulating factor (GM-CSF) therapy for patients with myelodysplastic syndromes and a relatively low risk of acute leukemia
}

\author{
R. Willemze', N. van der Lely, H. Zwierzina, S. Suciu, G. Solbu, H. Gerhartz, B. Labar, G. Visani, \\ M. E. Peetermans, A. Jacobs, P. Stryckmans, P. Fenaux, H. L. Haak, M. M. Ribeiro, E. Baumelou, \\ M. Baccarani, F. Mandelli, B. Jaksic, A. Louwagie, A. Thyss, M. Hayat, F. de Cataldo, A. C. Stern², \\ and R. Zittoun on behalf of the EORTC Leukemia Cooperative Group \\ ${ }^{1}$ Department of Hematology, Leiden University Medical Center, Leiden, The Netherlands \\ ${ }^{2}$ Sandoz Pharma Ltd, Basel, Switzerland
}

Ann Hematol (1992) 64: 173-180

Unfortunately a printing error has been introduced in this article. Instead of the $\tau$ statistic (Kendall's test, which is a non-parametric test), an $\mathbf{r}$ has been printed, which may be confused with the Pearson's test, a parametric statistical test, which is used to detect linear correlation between variables having a normal distribution. 